\title{
Radiation enhancement of laser palliation for advanced rectal and rectosigmoid cancer: a pilot study
}

I R Sargeant, J S Tobias, G Blackman, S Thorpe, S G Bown

\begin{abstract}
Laser palliation for advanced rectal or rectosigmoid cancer requires repeat treatments every four to six weeks. Thirteen patients (seven men, six women) age range 65-91 (median 81) received additional external beam radiotherapy in an attempt to reduce the frequency of laser treatments required. After successful laser recanalisation, patients were treated with a dose of 30-55 Gy in 10-20 fractions. Bowel symptoms were well controlled for prolonged periods in 11 patients $(85 \%)$ and further laser procedures were only required every 19 weeks median (range 6-53 weeks). The laser energy required after radiotherapy was only $800 \mathrm{~J} /$ month (median). Survival was 14 months (median, range $2 \cdot 5-20$ months) for the seven patients who have died. Seven patients received laser treatment only for three months or more (median 14 weeks, range 13-39). In this group control of symptoms required procedures every four weeks (median) before radiotherapy and 20 weeks (median) afterwards. The laser energy required before radiotherapy was $15000 \mathrm{~J} /$ month and $2000 \mathrm{~J} /$ month afterwards (Wilcoxon rank sum test, $\mathrm{p}<\mathbf{0 . 0 1}$ for both). Radiotherapy was well tolerated in all but one patient. Three patients developed strictures after radiotherapy but all were dealt with endoscopically. There were no complications solely due to endoscopic procedures. Additional radiotherapy enhances laser palliation for inoperable rectal or rectosigmoid cancer.

(Gut 1993; 34: 958-962)
\end{abstract}

The treatment of choice for rectal and rectosigmoid cancer is complete surgical resection. Unfortunately many patients present with tumours too extensive to resect or they are unfit for such surgery. The proportion of patients in this group varies between studies but is over $10 \% .^{12} \mathrm{~A}$ further group with anastomotic recurrences are often unsuitable for further surgery. Palliative resection carries a high morbidity and a mortality of $10-30 \% .^{12}$ The survival after palliative surgery is limited; one study $^{3}$ found a median survival of only eight and 14-16 months in such patients with and without liver metastases. A recent review ${ }^{4}$ advises that surgeons should treat surgically incurable patients with local methods only, which are both cost effective and carry a low morbidity and mortality. Nd YAG laser treatment for inoperable rectal and rectosigmoid cancer offers good palliation. ${ }^{5-9}$ Troublesome symptoms such as bleeding, discharge, tenesmus, and constipation (due to partial obstruction) can be controlled in most patients with minimal morbidity. One study ${ }^{10}$ reported less satisfactory results although these may be at least partly explained because patients were not brought back as often for follow up treatments as in other studies. Repeat sessions every four to six weeks are required for good control of symptoms. This is not surprising as the Nd YAG laser is only capable of safely treating intraluminal tumours. Treatment debulks the tumour and has an immediate beneficial effect on bleeding and discharge but disease is left in the rectal wall and beyond the lumen in local nodes so tumour regrowth occurs fairly rapidly. Radiotherapy, however, has the potential for treating the entire tumour and local regional draining sites and thus should be complementary. "It has an established record in the treatment of rectal cancer and is commonly used as adjuvant treatment after operation for Dukes B and C cancers. The risk of local recurrence in this setting is reduced and a randomised MRC trial looking at survival is presently in progress. ${ }^{12}$ Results from the first major series of patients treated by radiotherapy alone for rectal cancer were published in $1956 .{ }^{13}$ Symptomatic palliation was achieved in most patients but complications were common. Half of the patients required colostomies either due to obstructive symptoms before radiotherapy or from radiation induced fibrosis. Since that time there have been several studies with more modern radiotherapy techniques and fractionation to minimise complications and maximise symptom control for advanced cancers. ${ }^{14-16}$ Although symptoms can be controlled in most patients it takes several weeks for maximal effect and prolonged relief requires higher radiation dose regimes. These carry a higher risk of complications such as radiation swelling or fibrosis, which can in turn lead to obstruction and may even require permanent colostomy. By laser treatment and radiotherapy we aimed to achieve the benefits of both while minimising complications. Laser treatment can offer rapid relief of rectal discharge and obstructive symptoms, which should reduce the risk of obstruction from radiation induced swelling or fibrosis. Radiotherapy often relieves pain that is untreatable with laser, and may give better long term control so that repeat laser procedures are required less often. A recent pilot study with combined laser treatment and radiotherapy in oesophageal cancer $^{17}$ produced promising results. Here we present the results of a prospective pilot study of combination laser and radiotherapy for palliation of advanced rectal cancer. 


\section{Patient and methods}

\section{PATIENT SELECTION}

Forty seven patients with rectal and rectosigmoid tumours referred for laser treatment during an 18 month period between February 1990 and August 1991 were considered for inclusion in this study. All patients had been considered unsuitable for surgery either due to incurable disease (documented distal metastases or advanced locoregional disease), or high surgical risk such as advanced age or severe cardiorespiratory disease; $80 \%$ were tertiary referrals. The figure gives a detailed breakdown of patients included and excluded from the study.

After further assessment six patients were considered to be inappropriate referrals and were returned for surgery (two total obstruction, one tumour invading anus, three fit for surgery and resectable by anterior resection). A further eight patients with villous adenomas but no evidence of malignant change were deemed unsuitable for the study and were given laser treatment only.

Of 32 patients with proved cancer given laser treatment $12(38 \%)$ were entered into the study. Reasons for exclusion in this group were large liver metastases (seven), carcinoma but considered unfit for radiotherapy (seven, including two sigmoid lesions), refusal of radiotherapy

Flow chart: all referrals with rectosigmoid neoplasia.

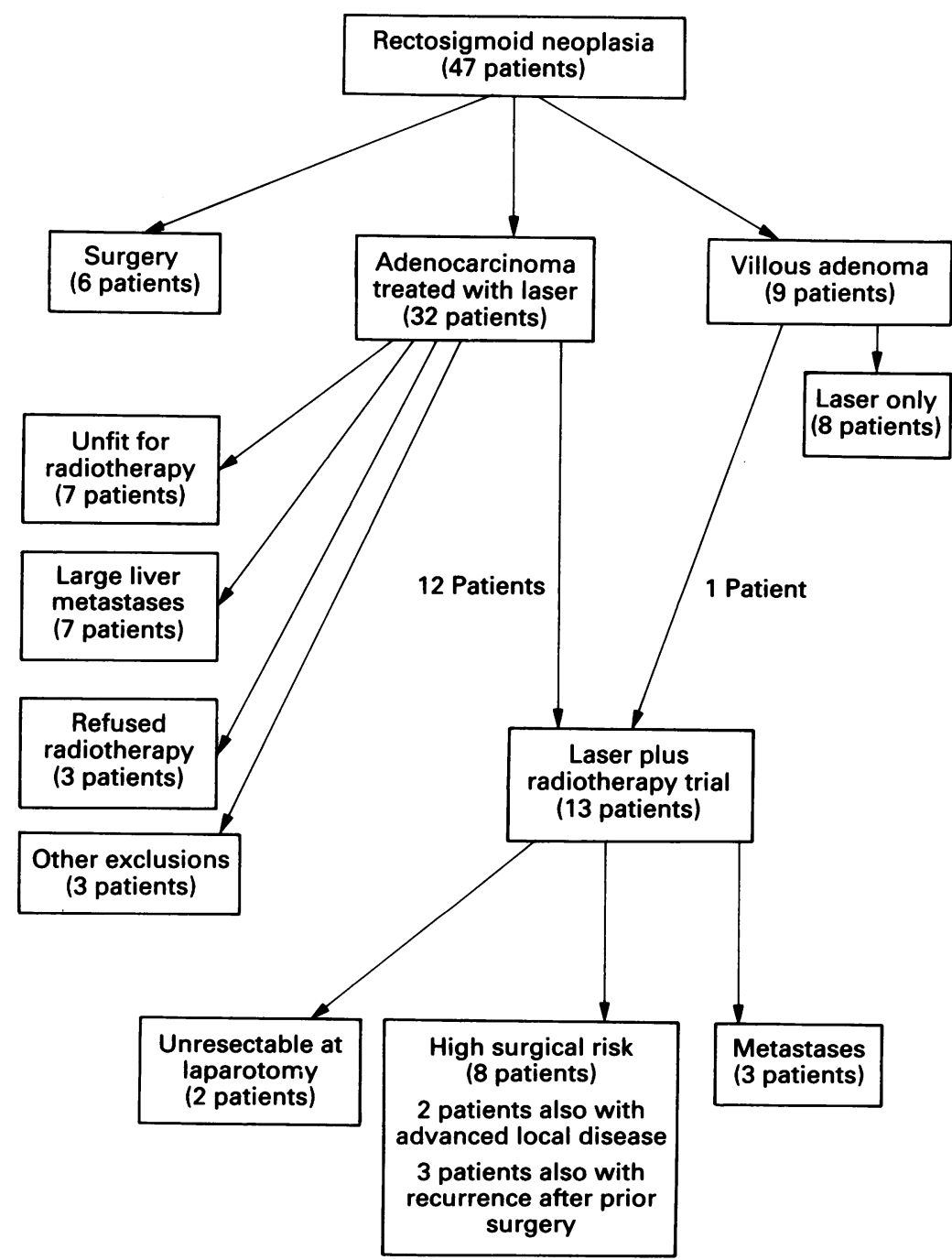

vaginal fistula (one), unable to pass stricture (thus radiotherapy likely to induce obstruction) (one). Thirteen patients (seven men, six women) age range 65-91 (median 81) were considered suitable for radiotherapy by the radiotherapist (JST) after a good initial laser result. All these patients had presented with rectal discharge or bleeding, nine also had diarrhoea and two had obstructive symptoms. Two also had tenesmus.

Eleven of these patients had rectal or rectosigmoid adenocarcinoma (including one with cancerous change in a villous adenoma), one had direct rectal invasion from cervical cancer, and one an extensive villous adenoma (with no documented focus of adenocarcinoma). Eleven were considered unfit for surgery including three with metastases and three recurrences after surgery, two of whom had rectal stump recurrences after abdominoperineal resections. The other two tumours were unresectable at laparotomy. The tumour length was $2-14 \mathrm{~cm}$ (median $5 \mathrm{~cm}$ ) and the lower margin of the tumour was at 0-14 cm (median $6 \mathrm{~cm}$ ) from the anal verge. At least six patients with lesions less than $7 \mathrm{~cm}$ from the anal margin would have required permanent colostomy if palliative resection had been carried out. Eight patients had circumferential lesions (C3) and five had $1 / 3-2 / 3$ circumferential lesions (C2).

ENDOSCOPIC TECHNIQUE

Whenever possible treatments were performed on an outpatient basis. A sodium phosphate enema is usually adequate preparation for rectosigmoid lesions; more proximal lesions required rectal washout or occasionally full bowel preparation. The technique is as for treating oesophageal cancers and has been published previously. ${ }^{9}$

\section{RADIOTHERAPY}

All patients were irradiated by supervoltage teletherapy (cobalt 60 ). The target volume was generally determined by computed tomography scanning and, if necessary, barium studies and treatment was delivered with anterior and posterior opposed fields in all cases. Dosage was decided on the basis of the patient's general condition, more radical regimes being offered to the younger and fitter patients. Ten received a dose of $30 \mathrm{~Gy}$ in 10 fractions and one patient was retreated with the same dose when rectal discharge recurred after nine months. One patient received $40 \mathrm{~Gy}$ in 20 fractions and a further two patients received doses of 50 and $55 \mathrm{~Gy}$ in 20 fractions. All treatments were given on consecutive days (weekends excepted).

\section{PATIENT FOLLOW UP AND EVALUATION}

Ten patients underwent check sigmoidoscopy three to six weeks after radiotherapy was completed. Response to radiotherapy was assessed and further laser treatment performed if a viable tumour was identified. Three patients did not return for a check as they were free of symptoms. Patients with little or no residual intraluminal tumour and a good lumen (implying minimal 
risk of obstruction) were not given a further follow up appointment. Those with tumour regrowth requiring laser energy of around $5000 \mathrm{~J}$ or more and those with a stricture that would not immediately allow passage of an endoscope were given a follow up appointment at four to six weeks for repeat laser endoscopy. This was essential because if there is a possibility of obstruction developing it is inappropriate in this patient group to wait for symptoms to develop. Inevitably, follow up appointments were given to some extent on a subjective basis according to the laser endoscopist's previous experience. As all these procedures were carried out by two endoscopists (IRS and SGB) we do not consider that this led to significant bias. All patients were subsequently contacted monthly by the research nurse (ST) to document progress and assess the necessity for further treatment. Patients were evaluated according to endoscopic result, early and late functional success, necessity for repeat endoscopic treatment, and dose rate of laser energy required to control intraluminal tumour (averaged laser energy per month).

\section{STATISTICAL METHODS}

Paired data for laser energy per month required and for frequency of endoscopic treatment before and after radiotherapy were analysed with the Wilcoxon signed rank test.

\section{Results}

Table I gives a summary of the results for endoscopic and symptomatic success.

TABLE I Endoscopic and symptom results

\begin{tabular}{llll}
\hline & $\begin{array}{l}C 2 \text { tumour } \\
(n=5)\end{array}$ & $\begin{array}{l}C 3 \text { tumour } \\
(n=8)\end{array}$ & All tumours \\
\hline Endoscopic result at check & 3 Good & 5 Good & 8 Good \\
& 2 No check & 2 Strictures & 2 Strictures \\
Early functional success & $5 / 5$ & 1 No check & 3 No check \\
Late functional success & $5 / 5(100 \%)$ & $8 / 8$ & $13 / 13$ \\
\hline
\end{tabular}

$\star$ This patient benefited from late functional success.

TABLE II Treatment interval data in weeks before and after radiotherapy

\begin{tabular}{lcll}
\hline & $\begin{array}{l}\text { Treatment } \\
\text { invervals in weeks } \\
\text { (C2 tumours) }\end{array}$ & $\begin{array}{l}\text { Treatment } \\
\text { intervals in weeks } \\
\text { (C3 tumours) }\end{array}$ & $\begin{array}{l}\text { Treatment intervals in } \\
\text { weeks (all tumours) }\end{array}$ \\
\hline $\begin{array}{l}\text { Pre-DXRT (7 patients followed up } \\
\text { for >3 months before DXRT) }\end{array}$ & $6-8$ (median 7) & $3-4$ (median 4) & $3-8^{\star}$ (median 4) \\
$\begin{array}{l}\text { Post-DXRT (7 patients as above) } \\
\text { Post-DXRT procedure interval (all } \\
\text { 13 patients) }\end{array}$ & $\begin{array}{c}20-41 \text { (median 39) } \\
9-14 \text { (median 19) }\end{array}$ & $\begin{array}{l}6-53 \text { (median 20) } \\
6-53 \text { (median 10) }\end{array}$ & $\begin{array}{l}6-53^{\star} \text { (median 20) } \\
6-53 \text { (median 19) }\end{array}$ \\
\hline
\end{tabular}

${ }^{\star} \mathrm{p}<\mathbf{0 . 0 1}$, Wilcoxon signed rank text.

DXRT =Deep $x$ ray therapy.

TABLE III Laser energy requirements before and after radiotherapy (excluding initial recanalisation)

\begin{tabular}{|c|c|c|c|}
\hline & $\begin{array}{l}\text { Laser energy (C2 } \\
\text { tumours) } \\
\text { Median (range) }\end{array}$ & $\begin{array}{l}\text { Laser energy (C3 } \\
\text { tumours) } \\
\text { Median (range) }\end{array}$ & $\begin{array}{l}\text { Laser energy } \\
\text { (all tumours) } \\
\text { Median (range) }\end{array}$ \\
\hline $\begin{array}{l}\mathrm{J} / \text { month pre-DXRT ( } 7 \text { patients } \\
\text { followed up for }>3 \text { months prior to } \\
\text { DXRT) }\end{array}$ & $\begin{array}{l}5000 \\
\quad(2500-13000)\end{array}$ & $\begin{array}{l}22000 \\
\quad(5000-26000)\end{array}$ & $\begin{array}{l}15000 \\
\quad(2500-26000)^{\star}\end{array}$ \\
\hline $\begin{array}{l}\mathrm{J} / \text { month post-DXRT ( } 7 \text { patients as } \\
\text { above) } \\
\mathrm{J} / \text { month post-DXRT (all } 13 \text { patients) }\end{array}$ & $\begin{array}{l}500 \\
(0-800) \\
0 \\
(0-800)\end{array}$ & $\begin{array}{c}3500 \\
(0-8000) \\
2000 \\
(0-8000)\end{array}$ & $\begin{array}{l}2000 \\
(0-8000)^{\star} \\
800 \\
(0-8000)\end{array}$ \\
\hline
\end{tabular}

${ }^{\star} \mathrm{p}<0.01$.

\section{ENDOSCOPIC DATA}

All patients seen for check endoscopy had good control of symptoms at that time. Eight had minimal or no tumour present at endoscopy and the endoscope passed through the stricture with no difficulty. (None of these patients required more that $2000 \mathrm{~J}$ laser treatment at this time.) In this group further procedures were performed when recurrent symptoms occurred (median every 20 weeks, range 6-42 weeks). The remaining two patients had tight strictures with obvious tumour shrinkage. The stricture was clearly infiltrated with tumour in both these patients and further laser therapy was required in order to pass the endoscope above the level of the stricture. These two required regular follow up to prevent them obstructing. They had procedures on average every 10 weeks for a follow up of 15 and 16 months to death. (One with liver metastases and one tumour cachexia).

Three patients declined to come for a check endoscopy immediately after radiotherapy as they had no bowel symptoms. Two of them never required further endoscopy as their local bowel symptoms remained well controlled (survival 2.5 and 14 months). The third, a 69 year old patient with an inoperable rectosigmoid cancer, underwent further laser treatment 10 months after radiotherapy when she developed recurrent rectal discharge. This was controlled with $5000 \mathrm{~J}$ laser energy after which the patient had no further rectal symptoms to death six months later. (She did, however, also have some chemotherapy the details of which are unknown).

\section{SYMPTOMS}

Laser treatment was considered to be successful if symptoms caused by intraluminal tumour were reduced to an extent that enabled the patient to lead a lifestyle appropriate to his or her age and general condition without constant concern for bowel function. Initial laser treatment had been successful and bowel symptoms were well controlled for the first two months after radiotherapy in all patients. Long term success (to date or to death) was achieved in 11 of 13 (85\%) patients.

One long term symptomatic failure occurred in a demented 81 year old man who presented with obstructive symptoms and rectal discharge and was found to have a circumferential rectal lesion. He did well for a year before developing intermittent rectal incontinence. This may be at least partially related to his dementia as the tumour appeared well controlled endoscopically. $\mathrm{He}$ is alive and under follow up and surgery was not deemed appropriate due to his generally weak condition. The second failure occurred in a 77 year old man who presented with severe secretary diarrhoea ( 15 motions per day), hypokalaemia, hyponatraemia, and prerenal failure. He had a $14 \mathrm{~cm}$ circumferential villous adenoma but no focus of malignancy was detected on repeated biopsies. Surgical resection proved impossible after he had a cardiac arrest on the operating table. He underwent 11 laser procedures before radiotherapy. Laser alone controlled the discharge and fluid and electrolyte 
loss and the tumour length shrank from $14 \mathrm{~cm}$ to $8 \mathrm{~cm}$. Laser procedures were required, however, every four weeks. Initially symptoms were well controlled after radiotherapy but the mucus discharge became troublesome again after two months. The patient was reluctant to have further surgery but eventually agreed. The second procedure went smoothly (as the fluid and electrolyte problems remained controlled after laser and radiotherapy treatment), an abdominoperineal resection was performed and the patient remains well six months later. Histology of the surgical specimen showed no cancer.

\section{TREATMENT REQUIREMENTS}

Whenever possible laser and radiotherapy were performed on an outpatient basis although many patients came from long distances so radiotherapy had to be given as an inpatient. Days in hospital ranged from nil to 52 (median 20 days). Overall the number of laser treatments required ranged from zero to 20 (median five). The number before radiotherapy was one to nine (median two) and after radiotherapy nil to 11 (median three). Table II shows the laser treatment intervals required to control symptoms. The treatment intervals before radiotherapy are given for the patients who were followed up for three months or more while undergoing laser treatment. This period was chosen as we considered that it was the minimum required to obtain a good baseline for treatment frequency and laser energy requirements for good tumour control. The initial treatment intervals start from the time of completion of the initial recanalisation, whether this took one or more treatments. Some patients were brought back routinely four weeks after recanalisation and most four to eight weeks after radiotherapy. The routine checks distort the data to some extent but because checks were performed both before and after radiotherapy the bias is minimised. The figures show a dramatic increase in treatment interval from four weeks before treatment to 20 weeks after, the treatment interval for C2 tumours being longer than that for $\mathrm{C} 3(\mathrm{p}<0.01)$. In terms of laser energy required to control symptoms (excluding initial recanalisation (Table III)) there was also a dramatic reduction in the figures per month required before and after radiotherapy indicating a corresponding reduction in the regrowth rate of intraluminal tumour bulk $(\mathrm{p}<0.01)$.

\section{SURVIVAL AND COMPLICATIONS}

To date 7 of $13(54 \%)$ of the patients in this study have died; survival in this group was 2.5-20 months (median 14 months). Six patients are still alive and have been undergoing treatment for 5.5-24 months (median 15 months). No serious endoscopic complications occurred. Radiotherapy was generally well tolerated. One patient suffered with transitory lethargy during treatment, which may have been related to radiotherapy. Three patients developed fibrous or neoplastic strictures after radiotherapy. All were dealt with endoscopically. One, in a 91 year old woman with inoperable rectal cancer, was particularly tight and required follow up laser treatment every six weeks. She eventually died after 65 weeks of successful treatment, with severe cachexia and large bowel obstruction. At the end, her general condition was considered to be too poor to justify a defunctioning colostomy.

\section{Discussion}

Laser treatment is now established in many units for palliation of symptoms in patients with inoperable rectal cancer. It is effective in $80 \%$ and is a particularly gentle and safe treatment not requiring general anaesthesia and carries a low risk of serious complications. ${ }^{9}$ The problem of the need for frequent follow up procedures is, however, a major one as this is inconvenient and sometimes distressing for the patient. Laser treatment can be technically difficult, particularly in patients in whom the endoscope will not pass the stricture. It usually takes longer than with oesophageal tumours and constitutes a considerable workload. This small pilot study shows promising results for the combination of laser and radiotherapy rectal and rectosigmoid cancer. The treatments should be complementary, laser treatment to give rapid relief of troublesome discharge and obstructive symptoms and radiotherapy to attack the entire tumour bulk, and this seems to be confirmed. Also, endoscopic treatment has the advantage of pre-emptying the obstruction that may result from radiotherapy. Both endoscopic and symptomatic results were impressive.

Only two patients in this study failed to achieve long term functional success. The patient with a villous adenoma had a very extensive lesion which was initially $14 \mathrm{~cm}$ long and it was a notable success to control his troublesome rectal discharge at all. Even he had definite symptomatic and endoscopic benefit from additional radiotherapy and his general condition improved enough for him to undergo successful surgery. The reduction in follow up procedures to one every 20 weeks or so for $\mathrm{C} 2$ tumours and 10 weeks or so for C 3 tumours is a useful improvement in follow up requirements.

The reduction in laser energy per month required for good symptom control is another indicator that suggests benefit from radiotherapy. Only 12 of 32 patients referred with rectal or rectosigmoid cancer who received laser therapy during the 18 month period were entered into this study. We were reluctant to submit patients with very poor prognosis to a two week course of radiotherapy and the small proportion entered reflects the extent of disease and poor general condition in this elderly group who are referred for laser treatment. The median survival of a year or more with symptoms controlled in most of those treated represents a very satisfactory outcome. Despite the development of radiation strictures in three patients none required open surgery. All were controlled for long periods with endoscopic treatment although it is possible that obstruction contributed to death in one patient.

There are several other treatments available for palliation of rectal and rectosigmoid cancer; 
these include electrocoagulation, ${ }^{19}$ transanal resection, ${ }^{20}$ and cryotherapy. ${ }^{21}$ They are all more aggressive than treatment with laser and carry a higher risk of complications and only cryotherapy can be performed without general anaesthesia. All of these treatments, however, suffer from the same inability to reach tumour outside the bowel wall. It is likely that a combination of these modalities with radiotherapy might also be complementary. To further clarify the benefit of the combination of topical techniques for tumour destruction and external beam radiotherapy randomised studies are required.

I R Sargeant, S G Bown, and S Thorpe were supported by the Department of Health Special Medical Development on Lasers and $S \mathrm{G}$ Bown by the Imperial Cancer Research Fund.

1 Goligher J. Surgery of the anus, rectum and colon, 5th ed. London: Bailliere Tindall, 1984: 741-3.

2 Lewis AAM, Khoury GA. Resection for colorectal cancer in the very old: are the risks too high. $B M \mathcal{F} 1988 ; 296: 459-61$.

3 Hohenburger W, Alterndorf A, Hermanek P Jr, Gall FP. Th laser in gastroenterology: malignant tumours in the lowe gastronintestinal tract-therapeutic alternatives. Endoscopy 1986; 18 (suppl 1): 47-52.

4 Alexander-Williams J. Advanced rectal cancer. New techniques are now available for conservative and palliative management. $B M \mathcal{F} 1990$; 300: 276-7.

5 Bown SG, Barr H, Matthewson K, Hawes R, Swain CP, Clarke CG, et al. Endoscopic treatment of inoperable colorectal cancers with the Nd-YAG laser. Br F Surg 1986; 73: $949-52$.

6 Mathus-Vliegen EMH, Tytgat GNJ. Nd YAG laser photocoagulation in gastroenterology: its role in palliation of colorectal cancer. Lasers in Medical science 1986; 1: 75-80.
7 Brunetaud JM, Maunoury V, Ducrotte P, Cochelard D, Cartot A, Paris JC. Palliative treatment of rectosigmoid carcinoma by endoscopic laser photoablation. Gastroenterology 1987; 92: 663-8.

8 Houton AD, Allen A, Mason R, McColl I. Laser treatment to rectal malignancies. Surgical Research Communications 1989 6: $271-3$.

9 Loizou LA, Grigg D, Boulos PB, Bown SG. Endoscopic Nd YAG laser treatment of rectosigmoid cancer. Gut $1990 ; 31$ : YAG laser.

10 Van Custem E, Boonen A, Goeboes G. Risk factors which determine long term outcome of Neodymium-YAG laser palliation of colorectal carcinoma. Int $\mathcal{F}$ Color Dis 1989; 4 9-11

11 Tobias JS, Bown SG. Palliation of malignant obstruction - Use of lasers and radiotherapy in combination. European fourna of cancer 1991; 27: 1350-2.

12 MRC 'AXIS' trial.

13 Williams IG, Horwitz $H$. The primary treatment of adenocarcinoma of the rectum by high voltage roentgen rays trays Therapy, and Nuclear Medicine. 76: 919-28.

14 Wang CC, Schulz MD. The role of radiation therapy in the management of carcinoma of the sigmoid, rectosigmoid and management of carcinoma of the
rectum. Radiology 1962; 79:5

15 Taylor RE, Kerr GR, Arnott SJ. External beam radiotherapy for rectal adenocarcinoma. Brf Surg 1987; 74: 455-9.

16 Allum WH, Mack P, Priestman TJ, Fielding JWL. Radiotherapy for pain relief in locally recurrent colorectal cancer. Ann R Coll Surg Eng 1978; 69: 220-1.

17 Sargeant IR, Loizou LA, Tobias JS, Blackman G, Thorpe S, Bown SG. Radiation enhancement of laser palliation for malignant dysphagia: a pilot study. Gut 1992: 33: 15971602 .

18 Madden JL, Kandalaft SI. Electrocoagulation as a primary curative method in the treatment of carcinoma of the rectum. Surg Gynecol Obstet 1983; 157: 164-79.

19 Berry AR, Souter RG, Cambell WB, Mortensen NJM Kattlewell MGW. Endoscopic transanal resection of rectal tumours - a preliminary report of its use. Br $₹$ Surg 1990 ; tumours -

20 Heberer G, Denecke H, Demmel N, Wirsching R. Local procedures in the management of rectal cancer, World $\mathcal{F}$ Surg 1987; 11: 499-503. 